\title{
Learning Platforms in the Context of the Digitization of Education: A Strong Methodological Innovation. The Experience of Latvia
}

\author{
Arta Rūdolfa and Linda Daniela
}

\begin{abstract}
The modernization of the education system, the digitalization of the educational environment and learning management systems (LMS), where one of the solutions is learning platforms, are the most urgent directions today's pedagogical work is taking to reap the benefits of the digital environment. Education quality can be improved in different ways: by changing the content of learning, forms of learning, learning methods and teaching aids; promoting the use of learning platforms in schools; introducing programming and robotics; using learning management systems and other systems. Technologies and digital solutions are transforming the educational landscape in technology-enhanced learning environments. On one hand, there are many possible solutions that provide technology-enhanced learning; while on the other, there is a need to transform educational processes, to transform competence in teaching, to analyze learning outcomes so that technology-enhanced environments can support knowledge construction. The authors of this paper analyze the results of research on learning platforms, in which several research methods were used: systematic literature analyses; development of learning platform evaluation tools; analyses of learning platforms; and surveys on teachers' attitudes to learning platforms. Altogether 705 teachers expressed their opinion on using learning platforms as a tool for enhancing knowledge construction, providing feedback and analyzing students' learning results. In this paper, the authors will discuss the results of analyses on nine learning platforms developed in Latvia, conducted using an evaluation tool with 22 criteria and 43 sub-criteria.
\end{abstract}

Keywords Learning platforms $\cdot$ Digital learning tool $\cdot$ Evaluation tool Evaluation criteria $\cdot$ Technology enhanced learning $\cdot$ Knowledge construction

\footnotetext{
A. Rūdolfa $(\bowtie) \cdot$ L. Daniela

Scientific Institute of Pedagogy, University of Latvia, Imantas 7th, 1, Riga, Latvia e-mail: arta.rudolfa@lu.lv

L. Daniela

e-mail: linda.daniela@lu.lv 


\section{Terminology in the Field of Digital Learning}

Digital solutions provide an opportunity for learning outside the specific boundaries of space. At the same time, pedagogical competences need to be developed so that digital solutions can be used in a targeted way to promote the acquisition of specific knowledge, skills and competences. One of the solutions for digital environments is the online learning opportunities that have entered the educational landscape thanks to the digital revolution. Digital solutions have advanced since 1971, with the mass production of the microprocessor by Intel [1], and continued with the definition of the World Wide Web in the 1980s and the first written web browser (WWW) in [2]—-the result of work by Berners-Lee and Cailliau [2] — and its launch for public use in 1993. Since then, various online solutions have been developed which in turn led to the online learning solutions known to the world by different terms: learning management systems (LMS), learning platforms (LP), massive open online courses (MOOC), online learning, digital education tools, etc. In 1924, Sidney Pressey offered to test a machine that resembled a typewriter. It could be used to train memory processes and answer test questions and predict whether a specific answer would be chosen [3]. LMS are systems designed to capture student information digitally, create learning content for students and analyze student activity, and student learning outcomes [4]. They are excellent tools for educators, and their main difference from learning platforms (LP) is that the curriculum is created by the educators themselves. This approach has both positive outcomes, as educators are free to offer different learning solutions, as well as negative ones, since the learning offering depends on the individual educator's skill at designing the materials. Massive open online courses (MOOC) on the other hand, are courses in which a key emphasis is that the content participants have access to and learn is available online. A learning platform (LP) is a solution that is somewhere between an LMS and a MOOC. Unlike LMSs, where content is created by the educators themselves and available to students, the content of LPs is developed by the platform developers and the offer includes access to it [5, 6]. MOOCs, on the other hand, offer ready-made content but do not provide the management facility that is available for both LMSs and LPs. However, these boundaries become less distinct and unambiguous as the technological solutions continue to evolve. The authors of this study will use the term "learning platforms" as it is not yet synonymous with other terms used.

\section{Teaching Conditions in Digital Learning Environments}

The use of different digital learning platforms in the pedagogical process is also an increasingly urgent necessity. This is because students should not only acquire knowledge but should also become active participants in the learning process, and 
creators of new innovations, technologies, and technological solutions. One important factor that transforms the teaching environment is students' ability and willingness to self-manage their learning. This is essential in situations where students can themselves use a variety of online materials to organize their learning. The digitization of the learning process means students will increasingly take responsibility for their own learning, thus becoming responsible constructors of their knowledge, with the ability to function independently in the future, according to the demands of the employment market. The scientific databases on learning platforms reveal the following different formulations for these systems: learning platforms; online learning; learning management systems; interactive learning, etc. In many respects, this is an indication that similar online digital solutions are being discussed. However, we can conclude that digital forms of learning can be considered digital learning tools and that, in order to be defined as an online learning platform, they must meet the basic criteria of providing:

- A curriculum that is relevant to the education program;

- Effective use of ICT - online access (on the most popular smart devices);

- Effective use of ICT (ease of use and navigation; ability to upload and download documents; ability to create training content; data protection and network login;)

- Some interactivity;

- The possibility to ask for and receive feedback (answer-explanation; analyzing different dimensions of learner progress and data; two-way communication; opportunities for peer-to-peer learning);

- Connectivity with other widely used educational digitalization solutions (LMS);

- Self-directed learning (it should be accessible, understandable, usable without the presence of a teacher; opportunity for students/pupils to organize their own learning process);

- Different teaching methods (gamification principles) [5].

Learning platforms are one way for students to benefit from online digital solutions. Learning platforms are a digital learning tool that provides access to information across time and space. Students effectively have access to training platforms anytime, anywhere [7]. Only 9 (out of 39) of the learning platforms analyzed and assessed in this study meet the key criteria for learning platforms (immediate feedback, self-directed learning, a degree of interactivity, HTML—online access, etc.) and were evaluated and tested in depth. It is important to keep in mind the definition for learning platforms that was developed during this study, based on the main criteria for learning platforms in general. This will avoid any further confusion concerning what this study is about and what type of digital learning platform it refers to. 
The learning platform is a digital, interactive online learning tool that incorporates learning content theory, exercises, tests, provides instant feedback and keeps track of a student's learning progress. Learning platforms should be easily accessible and easy to use for students, helping them to learn the content of a self-directed learning process and organizing teaching activities for teachers (Daniela \& Rudolfa, 2019).

\section{Methodology}

A study entitled "Learning platforms as a learning tool in the context of digitalization of education in Latvia" was carried out to understand the opinions of Latvia secondary school teachers regarding the use of available learning platforms and to develop recommendations for improving their operation. The study summarized and analyzed the teacher survey (705 respondents, 9 questions) to find out:

- Teachers' attitudes to learning platforms;

- The most frequently used training platforms;

- The main benefits;

- The main reasons for not using them.

In addition, this study analyzed learning platforms against specific criteria, to assess their pedagogical and technical potential. The evaluation tool (43 criteria) was applied to 39 online digital sites (used by the teachers themselves and named in the questionnaires referred to above), however most of the online sites mentioned by the teachers are not considered learning platforms.

The research steps were the following:

- Surveying teachers on the use of learning platforms;

- Developing and approving the training platform evaluation tool;

- Evaluating training platforms developed or adapted in Latvia.

\section{Learning Platform Evaluation Tool}

As there are many suggestions on how to organize online learning, and teachers and school administrators need criteria for choosing an appropriate LP, we developed an original evaluation tool. For this kind of assessment tool, in addition to the technical parameters and possibilities, it is mainly important to look at the pedagogical value produced [8]. The databases of the scientific literature provide very little information on what forms of evaluation can be applied to learning platforms. There is greater emphasis on the technological evaluation of LPs, but little information can be found 
on assessing their pedagogical content (even taking into account their technological aspects) [4, 9-11].

This tool is useful for assessing the pedagogical potential of LPs, provided that the evaluation is carried out by people who already have a certain degree of skill in the assessment of pedagogical processes. Other tools should be used to evaluate whether a platform supports learning outcomes, and to measure it in terms of knowledge growth [8].

The main objective of developing the evaluation tool was to further the use of meaningful, convenient and effective LPs in the modern teaching process. Learning outcomes are more important than the way learners acquire their knowledge. Thus, it is essential not only to analyze the technical and visual parameters of the training platforms, but also their educational value and pedagogical potential.

The evaluation tool considers the visual perceptibility, accessibility and interactivity of LPs, whether or not students can receive feedback, whether the content is updated regularly, and whether learners are given self-regulated learning opportunities. Another aspect for assessment could be the manageability of LPs and the possibility of creating new content. Most of the criteria are scored 0,1 or 2, but some are only evaluated in terms of whether the particular parameter is met (1 point) or not ( 0 points). The criteria for the evaluation tool came from analyzing the theoretical literature and various training platforms, and a combination of the authors' experiences. The tool was verified by using it to assess LPs used in Latvia [8].

The main factors to evaluate in LPs and their quality are:

- Compliance of content with the set curriculum

- Effective use of ICT —online availability (on the most popular smart devices)

- Usability and accessibility

- Degree of interactivity (interactive engagement is desirable)

- Provision of feedback (answer/explanation; analysis of student's progress)

- Compatibility with other digital tools

- Provision of two-way communication on the platform

- The use of the learning tool does not require the presence of adults, the tool is designed so that step by step "guides" the learner through the learning topics, it is easy to use (intuitive) [8].

Nine learning platforms used in Latvia and their score after being tested with evaluation tool (Fig. 1).

\section{Research Results}

The first quantitative method of data acquisition in empirical research is the survey. This method was chosen because the authors wished to get the opinions of as many respondents as possible regarding the use of learning platforms in Latvian secondary schools. The SPSS data mathematical statistical analysis program was used to analyze the data obtained from the questionnaire. 
Fig. 1 Learning platforms used in Latvia and analyzed within the framework of this study

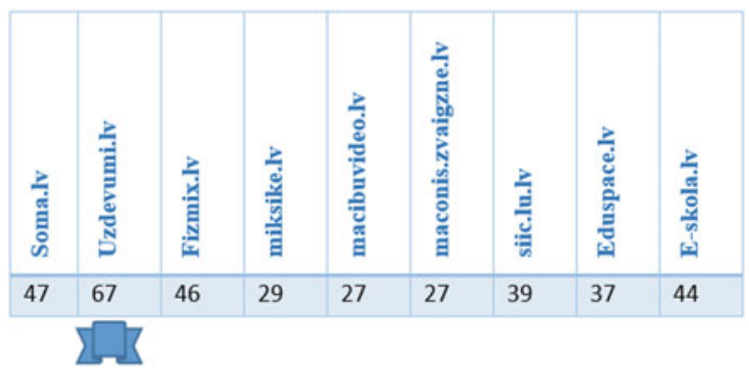

\subsection{Teachers Who Use Learning Platforms (N 573) Do So}

- To enable students to review what they have learned and consolidate their knowledge.

- To give students access to information in a convenient place and at a time that enables them to learn independently.

- To provide students with immediate feedback to promote their self-efficacy and thus encourage their willingness to engage in self-directed learning.

- Teachers who combine content on learning platforms with other forms of learning or who use content on learning platforms to assign individual tasks to students are also ready to develop new learning content; in other words, they take the current needs of their students into account and take advantage of the digital environment to instantly update curriculum content with the latest information.

- The most popular learning platform used by teachers is www.uzdevumi.lv (which can be translated as tasks.lv).

\subsection{Teachers Who Do not Use Learning Platforms in the Learning Process (N 79) Give These Reasons}

- Students already spend too much time on technology.

- Stereotypical statements that do not consider the benefits of using this learning tool, which is also associated with benefits for students, as evidenced by data correlation analysis.

- Claims of disliking the curriculum content; which, on the one hand, demonstrates a desire to retain control over student learning and distrust of self-directed learning, while, on the other, demonstrates stereotypical beliefs, since it is impossible for them to have a fact-based understanding of the content of learning platforms, if they do not use them.

(3) Despite the generally positive attitude to the place and role of learning platforms in the learning process, these experts who express their personal views on learning platforms also highlighted the issue that happens that learning platforms 
offer low-complexity tasks that can sometimes mislead learners (e.g., in a situation when the student completes 5 tasks from a topic and he/she gets the idea that the topic has been mastered, because the platform does not offer a deeper learning/task level). This can lead to simplified memory-enhanced development (positive) but also to underdevelopment of higher thinking levels (metacognition), thus emphasizing the need for continuous critical evaluation of the content hosted on learning platforms. But it is important to understand that a much lower proportion of students requires the more difficult tasks, so creating such complex tasks would be disadvantageous for only a relatively small group of students. Uzdevumi.lv, for its part, is smartly adapted and performs the main functions successfully-acquisition of new content, review, homework, tests, reinforcing knowledge, spirit of competition, feedback, diagnostic tests of previous years delivered interactively with various tasks, and the pedagogical opportunities that have already been described.

\subsection{The Results from the Statistics on the Uzdevumi.Lv Learning Platform Show That}

- Students are prepared for a self-directed learning process, if they are given the opportunity; the data show that a large number of students connect to a learning platform after school, complete individually selected tasks and read the theoretical information there.

- Students using the PROF (paid) version spend twice as much time on learning tasks as students who have free access, which also confirms that they are able to self-learn if given the opportunity.

- Teachers using the PROF (paid version) develop more teaching materials and assign more tasks to students than users of the free version, suggesting that the former see the benefit of this type of learning and access to more interactivity on the learning platform.

\section{Conclusions}

1. Learning platforms are a way of promoting student-led learning and optimizing the work of teachers.

2. New and innovative teaching methods, forms of work, and transformed learning environments are necessary for preparing students for life in a constantly changing society, like today's.

3. Teaching platforms currently lack tasks that lead to sophisticated thinking operations; such tasks are expensive and are required by fewer students (possibly a niche in educational technology). 
4. It is important to define basic terms before we can understand the digitalization solutions of the educational environment and how to use them in the pedagogical process.

5. Modern pedagogy should look for ways to bridge the gap between how students learn and how teachers teach. Today's students process information differently from our ancestors, and these differences are wider and deeper than teachers have anticipated.

6. Learning outcomes are more important than the way students achieve them. Thus, it is essential to analyze the educational value and pedagogical potential. Any learning platform is a tool in the hands of an indispensable component of education-the teacher.

7. Training platforms should be evaluated every year as technology advances very rapidly.

\section{References}

1. Chan, T.W., Roschelle, J., Hsi, S., Sharples, M., Brown, T., Patton, C., et al.: One-to-one technology-enhanced learning: an opportunity for global research collaboration. Res. Pract. Technol. Enhanc. Learn. 1(1), 3-29 (2006)

2. Berners-Lee, T., Cailliau, R.: WorldWideWeb: proposal for a hypertext project (1990). Retrieved 12 July 2019

3. Watters, A.: The automatic teacher. Retrieved from: http://hackeducation.com/2015/02/04/theautomatic-teacher (2015)

4. Watson, W.R., Watson, S.L.: An argument for clarity: what are learning management systems, what are they not, and what should they become? TechTrends 51(2), 28-34 (2007)

5. Latvian Information and Communication Technology Association (LIKTA). Recommendations for the Development and Evaluation of Digital Teaching Resources and Resources (2015)

6 El Emrani, S., El Merzouqi, A., Khaldi, M.: Massive online open courses platforms: analysis and comparative study of some pedagogical and technical characteristics. Int. J. Smart Educ. Urban Soc. (IJSEUS) 10(1), 25-36 (2019)

7. OECD. Students, Computers and Learning. Making the Connection. Pieejams: https://read. oecd-ilibrary.org/education/students-computers-and-learning_9789264239555-en\#page4 (2015)

8. Daniela, L., Rūdolfa, A.: Learning platforms-how to make the right choice. In: Daniela, L. (ed.) Didactics of Smart Pedagogy: Smart Pedagogy for Technology Enhanced Learning, Springer, pp. 191-212 (2019). ISBN 978-3-030-01550-3

9. Dabbagh, N.: Pedagogical models for e-learning: a theory-based design framework. Int. J. Technol. Teach. Learn. 1(1), 25-44 (2005)

10. Dağ, F.: The Turkish version of web-based learning platform evaluation scale: reliability and validity study. Educ. Sci. Theor. Pract. 16(5), 1531-1561 (2016)

11. Edmunds, B., Hartnett, M.: Using a learning management system to personalise learning for primary school students. J. Open Flex. Distance Learn. 18(2), 11-29 (2014) 
Open Access This chapter is licensed under the terms of the Creative Commons Attribution 4.0 International License (http://creativecommons.org/licenses/by/4.0/), which permits use, sharing, adaptation, distribution and reproduction in any medium or format, as long as you give appropriate credit to the original author(s) and the source, provide a link to the Creative Commons license and indicate if changes were made.

The images or other third party material in this chapter are included in the chapter's Creative Commons license, unless indicated otherwise in a credit line to the material. If material is not included in the chapter's Creative Commons license and your intended use is not permitted by statutory regulation or exceeds the permitted use, you will need to obtain permission directly from the copyright holder.

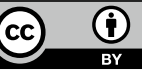

